\title{
Elements Contributing to Limited Participation of Disabled Children in School Based Sport Extracurricular Activities
}

\author{
Efrem Kentiba $^{1,2}$, Tesfay Asgedom ${ }^{3}$ \\ ${ }^{1}$ Department of Sports Science, Arba Minch College of Teachers' Education, Arba Minch, Ethiopia \\ ${ }^{2}$ Department of Sports Science, Mekelle University, Mekelle, Ethiopia \\ 3Department of Sports Science, Addis Ababa University, Addis Ababa, Ethiopia
}

Email address:

efre89@gmail.com (E. Kentiba)

\section{To cite this article:}

Efrem Kentiba, Tesfay Asgedom. Elements Contributing to Limited Participation of Disabled Children in School Based Sport Extracurricular Activities. International Journal of Sports Science and Physical Education. Vol. 2, No. 6, 2017, pp. 67-72.

doi: $10.11648 /$ j.ijsspe.20170206.11

Received: November 9, 2017; Accepted: November 23, 2017; Published: January 31, 2018

\begin{abstract}
Aim of the study is to assess "Elements contributing to limited participation of children with disabilities (CWDs) in school based sport extracurricular activities" using descriptive survey design. The study participants were purposely selected $(\mathrm{n}=36)$. Observation using check lists, semi structured questionnaires and structured interview was administered. And the data obtained was analyzed qualitatively and quantitatively. As the findings shows opportunities to participate in school based sport extracurricular activities are unequal among disabled and non-disabled children in schools which is in contrast with UN convention on the rights of persons with disabilities [12] which states to ensure that children with disabilities have equal access with other children to participation in play, recreation, leisure and sporting activities, including those activities in the school system. This limited CWDs to get the (Physical, Social and Psychological) benefits of participation in sport extracurricular activities. Lack of opportunities for participation, disability sport competitions at school level, poor facilities, poor school compound, poor student to student support and lack of awareness on including CWDs in sport activities are found as contributing elements. Recommendations: support professional development and mentorship opportunities for volunteer staffs, physical education teachers and create awareness on inclusive issues, all members of the sport extracurricular activities should be tasked with ensuring that CWDs feel welcome to participate, promote sports that embrace diversity and open them to all participants regardless of ability, pair CWDs with partners without disabilities on teams for competition and schools should prepare disability sport competitions as they prepare for non - disabled ones, by doing this, they can show the ability of disabled students.
\end{abstract}

Keywords: Extracurricular Activities, Children with Disabilities, Sport, Participation

\section{Introduction}

Extracurricular activities are school based organized student activities typically carrying no academic credit [1]. Middle childhood, ranging from age 7 to 12 , is an age phase clearly distinct from earlier childhood years and adolescence. The key developmental tasks defining this stage include the establishment of peer relations, acquirement of socially appropriate conduct, and forming the basis for academic achievement [2]. These skills can be developed in extracurricular activities, which usually offer experiences of teamwork and support the development of many social, cognitive, and physical skills [3].

Studies in the area indicate that both the type of extracurricular programs and level of participation may impact the individuals' development [4]. Students' participation in extracurricular activities is not common for children with disabilities [4]. Some evidence has been put forward suggesting that extracurricular activities might be particularly beneficial for at-risk populations [3].

In this study, the theoretical framework guiding research on extracurricular activities was based on Socio- Ecological Model which represents different strengths of association between different contexts of sport participation and the three health aspects (physical, psychological and social) [5] as 
cited by [6]. It also encourages a shift from a focus on single issues, risk factors and linear causality, towards a holistic concern to develop supportive contexts in the places that people live their lives. Many studies have investigated the influence of sport, as one type of extracurricular activity, on positive youth $(7,8)$ and personal development [9]. It plays key roles in promoting good citizenship; enhancing leadership, social and conflict resolution skills; developing positive peer relations; health promotion; teaching rules norms and values; promoting positive self-esteem and selfworth; decreasing antisocial behavior and engaging marginalized youth [10].

Conceptual Model

Based on the theoretical frameworks above, the study is based on the model developed by [6] namely health through Sport conceptual model.

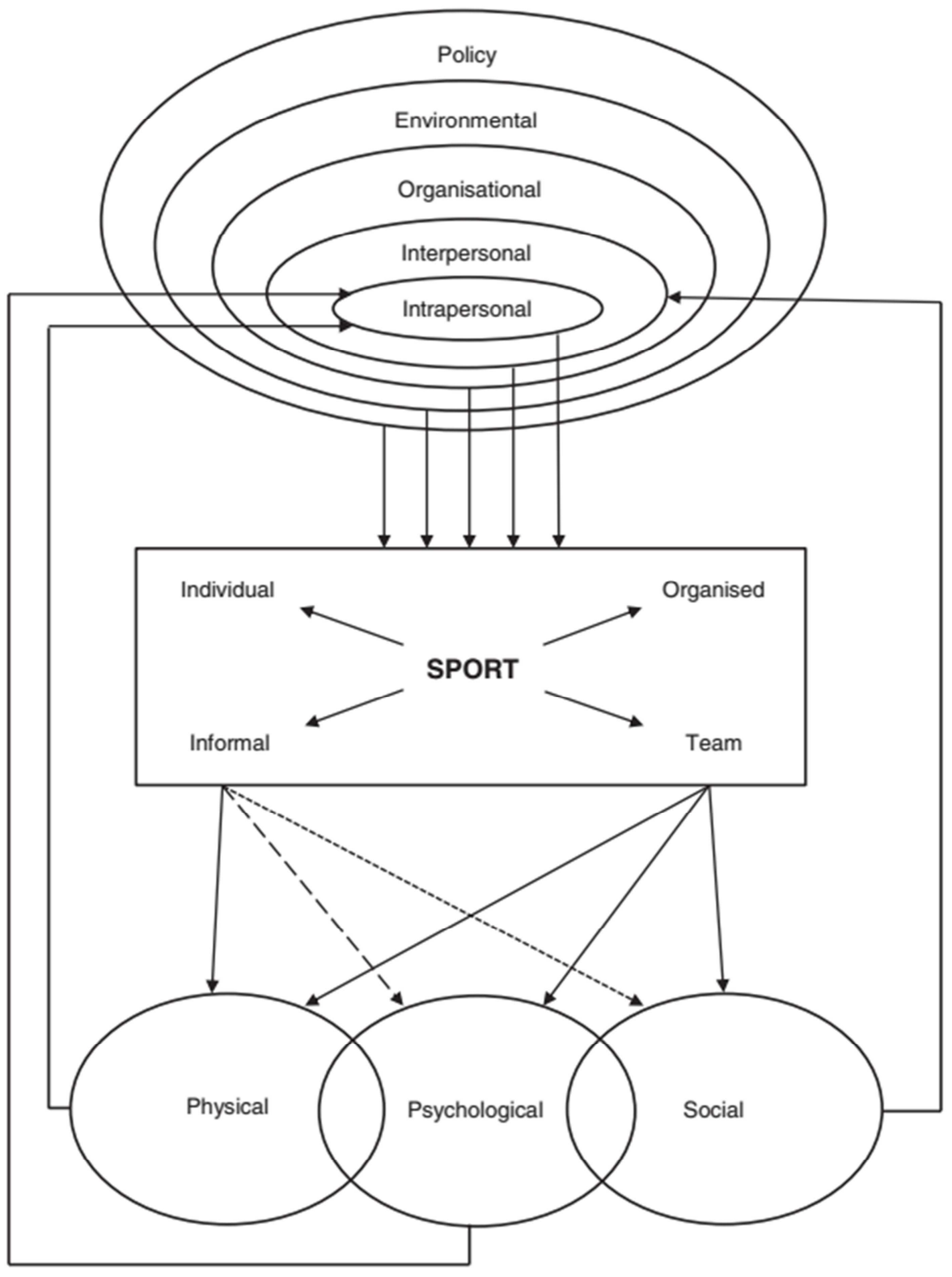

Figure 1. Health through sport conceptual model [6].

In Ethiopia, there is no adequate statistical data on the incidence of disability and the situation of children with disabilities (CWDs) in schools. According to UNICEF Ethiopia's disability program [11] report reliable information on disability in Sub Saharan Africa is difficult to find. As stated by Japan International Cooperation Agency (2002) it is estimated that $7.6 \%$ of the population lives with a disability (approximately 7 million). A separate WHO study estimates that it is $10 \%$, meaning that $>9$ million people are living with a disability.

Schools usually offer extracurricular and nonacademic activities, which typically involve students of the same age and may be organized and supervised by school personnel. Examples of these activities include the school sports and recreational activities, clubs like mini media, environmental protection, anti HIV, etc. For children with disabilities who qualify for special education, there is a need as to design and provide appropriate academic and appropriate extracurricular 
and nonacademic activities. It has been suggested by [4], that participation in voluntary, school based extracurricular activities increase school participation and achievement as acquisition of interpersonal skills and positive social norms, membership in pro-social peer groups, and stronger emotional and social connections. Students' participation in extracurricular activities is not common for children across disability groups [4]. Therefore, this study is aimed at assessing elements contributing to limited participation of disabled children in school based sport extracurricular activities.

\section{Methods}

\subsection{Participants}

The study sampled a total of 36 purposely selected participants. Out of this, 24 are primary school students and 12 teachers.

\subsection{Design}

Descriptive survey design with quantitative and qualitative research approaches. The design included triangulation of data collection by questionnaire, interview and observation. Information collected through questionnaires is interpreted quantitatively using tables, charts, percentages and frequencies.

\subsection{Sampling Method}

A non-probability sampling method is used through purposive techniques in order to capture information from a knowledgeable group of respondents.

\subsection{Method of Data Analysis}

Data analysis included descriptive statistical techniques using frequency counts, percentages tables and graphs, whereas, qualitative data were analyzed using words.

\section{Results and Discussion}

Table 1. Number of subjects.

\begin{tabular}{llll}
\hline \multirow{2}{*}{ Sex } & Subjects & & \multirow{2}{*}{ Grand Total } \\
\cline { 2 - 3 } & CWDs & Teachers & 34 \\
\hline Male & 10 & 9 & 9 \\
Female & 2 & 3 & 36 \\
Total & 24 & 12 & \\
\hline
\end{tabular}

Table 1. shows summary on demographic characteristics of respondents, the total number of participants is $(n=36)$, out of this 24 of them are children with disabilities (CWDs) 18 male and 6 female, there are also 12 teacher participants 9 males and 3 females.

Table 2. Disability type in sample schools.

\begin{tabular}{llllll}
\hline Types of disabilities & & & & & \\
\hline Visual Impairment & Hearing Impairment & Motor Disorder & autism & Mental Retardation & Languages disorders \\
\hline 4 & - & 16 & - & - & 4 \\
$17 \%$ & - & $66 \%$ & - & - & 24 \\
\hline
\end{tabular}

Table 2 shows types of disabilities in schools sampled. 17\% of the subjects are with visual impairments, $66 \%$ of them are with motor disorder including orthopedic impairments, and the $17 \%$ of them are with language impairments.

Table 3. Teacher subjects response on disability information in the schools.

\begin{tabular}{lllll}
\hline No & Item & Responses & No. & \% \\
\hline \multirow{4}{*}{1} & Is there an opportunity for & Yes & 1 & $8 \%$ \\
& students with disabilities to have & No & 8 & $66 \%$ \\
& access to school based sport & Not applicable & 3 & $24 \%$ \\
& extracurricular activities? & Total & 12 & \\
\hline
\end{tabular}

Results on table 3 shows teacher subjects' response on opportunity for students with disabilities to have access to school based sport extracurricular activities, $8 \%$ of the subjects replied yes, $66 \%$ of them replied no and the rest $24 \%$ replied not applicable. As the majority of subjects' response, there is less or no access to school based sport extracurricular activities for CWDs and the result is also in agreement with students' response for the same issue.

Table 4. Peer-to-peer support.

\begin{tabular}{lllll}
\hline No & Item & Responses & No. & \% \\
\hline \multirow{3}{*}{1} & Do disabled students get help & Yes & 3 & $25 \%$ \\
& from non-disabled students? & No & 9 & $75 \%$ \\
& & Total & 12 & 100 \\
\hline
\end{tabular}

Results in table 4 shows presence or absence of peer to peer support. $25 \%$ of the subjects replied that disabled children get help from non-disabled ones, whereas $75 \%$ of the respondents agreed that disabled children do not get any assistance from non-disabled counterparts. This shows poor peer to peer assistance. In line with this, students' subjects were interviewed similar issue as "do your friends invite you to play with?" and the results shows that non-disabled students don't invite disabled ones to play with. Again they were asked the reason why? The response was due to disability they have, and all agreed that "if I play with nondisable peer, they will lose games because I'm weak", this response is common for majority of the subjects.

Do disabled students get help from non disabled ones?

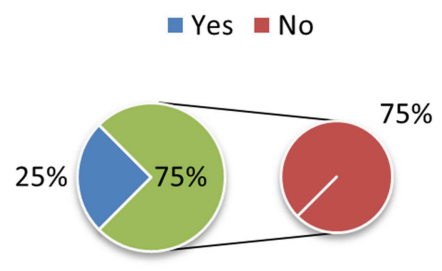

Figure 2. Level of support among disabled and non-disabled ones. 
Table 5. preparation of disability sport competitions.

\begin{tabular}{lllll}
\hline No & Item & Responses & No. & $\%$ \\
\hline & & Yes & - & - \\
& Does your school prepare & No & 12 & 100 \\
& disability sport competitions? & Total & 12 & 100 \\
\hline
\end{tabular}

Results in table 5 shows preparation of disability sport competitions by schools and in sample schools. $100 \%$ of the respondents replied there is no disability sport competition in their school. Concerning this the researcher believes that absence of such school activities would create little or no access for disabled students to take part in school based sport extracurricular activities.

Table 6. Participation of disabled students in school extracurricular activities.

\begin{tabular}{lllll}
\hline No & Item & Responses & No. & \% \\
\hline \multirow{2}{*}{1} & Do students with a disability have & Yes & - & - \\
& access to participate in extracurricular & No & 12 & 100 \\
& sport activities at your school? & Total & 12 & 100 \\
\hline
\end{tabular}

Does your school prepare disability sport competitions?

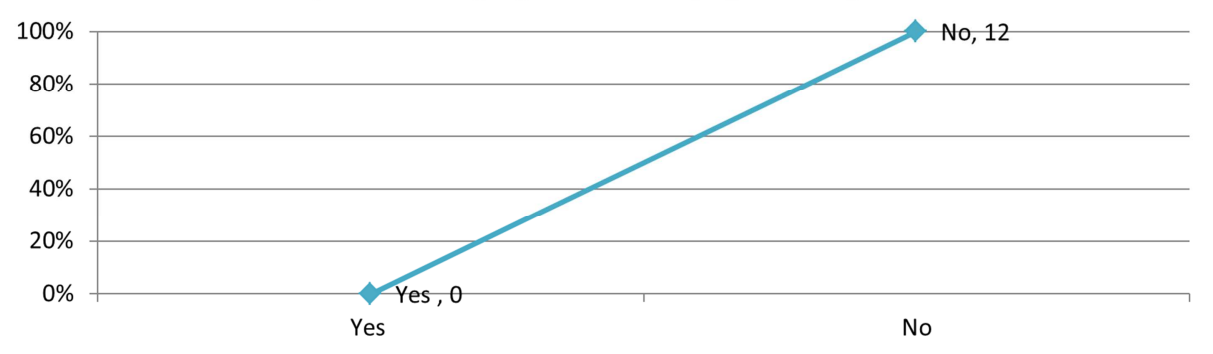

Figure 3. School disability sport competitions.

Table 6 shows participation of disabled children in sport extracurricular activities in schools, other studies shows that extracurricular activities are a part of students' everyday life. They play important roles in student's lives. They have positive effects on student's lives by improving behavior, school performance, school completion, positive aspects to make successful adults, and social aspects. In line with this from the table above the obtained data regarding extracurricular activities shows students with disabilities have no access to participate in school extracurricular activities at all, all the respondents or $100 \%$ of them said no at all. In line with this students with disabilities interviewed "Does your school sport clubs welcome you to take part in sport extracurricular activities?, therefore, except few subjects many of them said they don't invite to take part in it, whereas, two participants said if there are class friends in the clubs, they invite, but if no one who knows us is there then, they don't. Therefore, this is also in agreement with interview results of students with disabilities and nondisabled ones and field observation results in all schools under study. This is in contrast with UN convention on the rights of persons with disabilities [12] which states to ensure that children with disabilities have equal access with other children to participation in play, recreation and leisure and sporting activities, including those activities in the school system.

Table 7. perceptions towards possible elements affecting the participation of disabled students in school based sport extracurricular activities.

\begin{tabular}{|c|c|c|c|c|c|c|c|c|c|}
\hline \multirow{2}{*}{ No } & \multirow{2}{*}{ Elements } & \multicolumn{2}{|c|}{ Agree } & \multicolumn{2}{|c|}{ Uncertain } & \multicolumn{2}{|c|}{ Disagree } & \multicolumn{2}{|c|}{ Total } \\
\hline & & No. & $\%$ & No. & $\%$ & No. & $\%$ & No. & $\%$ \\
\hline 1 & Undesirable attitude and practices from non-disabled students & 8 & $67 \%$ & 3 & $25 \%$ & 1 & $8 \%$ & 12 & 100 \\
\hline 2 & Problems with roads to play grounds & 11 & $92 \%$ & 1 & $8 \%$ & - & - & 12 & 100 \\
\hline 3 & Poor or no facilities & 12 & 100 & - & - & - & - & 12 & 100 \\
\hline 4 & Disturbance of non-disabled students by disabled ones & 7 & $58 \%$ & 3 & $25 \%$ & 2 & $17 \%$ & 12 & 100 \\
\hline 5 & Absence of modified equipments & 9 & $75 \%$ & 1 & $8 \%$ & 2 & $17 \%$ & 12 & 100 \\
\hline 6 & Poor commitment from the school and other concerned bodies & 6 & $50 \%$ & 2 & $17 \%$ & 4 & $33 \%$ & 12 & 100 \\
\hline 7 & Disabled students lack of interest in sport, play and extracurricular activities & 2 & $17 \%$ & 2 & $17 \%$ & 8 & $66 \%$ & 12 & 100 \\
\hline 9 & Poor pupil to pupil support & 10 & $84 \%$ & 1 & $8 \%$ & 1 & $8 \%$ & 12 & 100 \\
\hline
\end{tabular}

Results in table 7 shows teachers perceptions towards possible elements affecting the participation of disabled students in school based sport extracurricular activities. Based on the obtained results negative attitude from others or non-disabled counterparts $67 \%$ of the subjects showed their agreement that the mentioned element affects the participation of disabled students school based sport in extracurricular activities, $25 \%$ of them showed their uncertainty and the rest $8 \%$ of them showed disagreement on the element mentioned. This is also in agreement with interview results of students' subjects and field observation results in all schools under study.

Regarding to elements associated with difficulties in roads to sport fields $92 \%$ of subjects showed their agreement as elements related to transport is one of those elements which limits their participation, whereas, $8 \%$ showed uncertainty and no disagreement showed on the issue. [2] Noted constraints related to equipment and the various ability levels of individuals with 
and without disabilities can influence the success or failure of participants in various programs. Concerning poor facilities and equipments, all of the subjects or $100 \%$ of them showed their agreement as these element affects the participation of students with disabilities in school based sport extracurricular activities, whereas, there is no uncertainty and disagreement in the element. Therefore, poor facilities or no facilities are one of the elements which affect the participation of students with disabilities in school based sport extracurricular activities. This is also in agreement with interview results of student subjects and field observation results in all schools under study.

Concerning lack of modified equipments, $75 \%$ of the subjects agreed that lack of such equipments highly affects the participation of disabled students in extracurricular activities; whereas $8 \%$ of them and $17 \%$ showed their uncertainty and disagreement respectively that lack of equipments have less or no impact on the partaking of disabled children in extracurricular activities. This is also in agreement with interview results of student subjects and field observation results in all schools under study.

Concerning disabled students lack of interest in extracurricular activities as a factor which hinders their own participation in extracurricular activities, $17 \%$ of the subjects showed their agreement, again $17 \%$ of them also showed uncertainty and the rest $66 \%$ of them showed disagreement. Based on the obtained result above on interviews with students we can conclude that, students' lack of interest doesn't affect their participation in extracurricular activities and the results is in opposite with students interview results.

Finally, concerning pupil to pupil interaction, studies support that there will always be some who will be happy to help by approaching them (disabled ones) from station to station, being their partner, talking to them during free time activities, playing in a modified game with modified equipments, or even going off to the side and practicing different activities with them [13]. Regarding this many of the respondents showed their uncertainty that such interaction among disabled and non-disabled students seems poor. This is also in parallel with interview results. Positive peer to peer relations are also supported by [13] which states as school is the primary social structure for children. Friendships and social relationships with peers are a central part of students' lives. A positive school environment encourages communication and interaction and does not tolerate harassment, bullying or violence of any kind.

\section{Conclusions}

The aim of the study was to seek out major elements contributing to limited participation of children with disabilities in school based sport extracurricular activities. Extracurricular activity participation is important in early school years, because children who participate in activities during middle childhood stages are more likely to continue to do so during adolescence [14]. And participation will benefit physical and psychosocial development of individuals and limited participation will also limit those benefits. The results showed that the opportunities to participate in school based sport extracurricular activities are unequal among disabled and non-disabled children which is in contrast with UN convention on the rights of persons with disabilities [12] which states to ensure that children with disabilities have equal access with other children to participation in play, recreation and leisure and sporting activities, including those activities in the school system.

Contributing elements for this limited participation includes, poor pupil to pupil support, lack of disability sport competitions in schools, poor facilities, playgrounds, school compound, modified equipments, limited access to school based sport extracurricular activities, lack of awareness on how to include people with a disability in sport and physical activities, poor commitment from school and concerned bodies to provide necessary supports to students with disabilities to enable them participate in school based extracurricular activities.

\section{Recommendations}

On the basis of the conclusions, the following recommendations were forwarded which will help physical education teachers, school directors, curriculum experts, students with disabilities and all concerned bodies in the process of taking away elements identified above.

1. Support professional development and mentorship opportunities for staff, educators, and volunteers from physical education teachers and create awareness on inclusive issues.

2. All members of the sport extracurricular activities should be tasked with ensuring that students with disabilities feel welcome to participate.

3. Create a sense of belongingness which includes celebrating diversity regardless of ability and ensuring that sports participation experiences are positive, social, fun, inclusive, non-judgmental and free of harassment and inappropriate language.

4. Promote sports that embrace diversity and open them to all participants regardless of ability.

5. Allow friends without disabilities access to modified sports equipment and skills development so that they may play and compete with peers who play these sports.

6. Pair students with disabilities with partners without disabilities on teams for competition in schools and elsewhere.

7. The schools should prepare disability sport competitions as they prepare for those non - disabled ones, by doing this, they can show the ability of disabled students.

8. Work in minimizing problems related with poor facilities, playgrounds, school compounds, and modified equipments; without paying much cost, simply by dealing with students' parents, governmental and nongovernmental organizations they can solve such problems associated with such issues. 


\section{Future Research Directions}

1. Other depth research needs to be conducted using large samples.

2. Experimental studies needs to be conducted using physical, psychological and social variables.

\section{References}

[1] Brown MD. Science or soccer? -- how important are extracurricular activities? Education World website. 2000.

[2] Masten, A. S., \& Coatsworth JD. The development of competence in favorable and unfavorable environments. Am Psychol. 1998; 53: 205-20.

[3] Pulkkinen R-LM\& L. The benefits of extracurricular activities for socioemotional behavior and school achievement in middle childhood: J Educ Res. 2014; 6 (3): 10-33.

[4] Eccles, J. S., Barber, B. L., Stone, M., \& Hunt J. Extracurricular activities and adolescent development. J Soc Issues. 2003; 59 (4): 865-89.

[5] McLeroy K, Bibeau D, Steckler A GK. An ecological perspective on health promotion programs. Heal Educ Q. 1988; 15 (4): 351-377.

[6] Eime RM, Young JA, Harvey JT, Charity MJ, Payne WR. A systematic review of the psychological and social benefits of participation in sport for children and adolescents : informing development of a conceptual model of health through sport.
Int J Behav Nutr Phys Act. 2013; 10 (1): 1.

[7] Zarrett N, Fay K, Li Y, Carrano J, Phelps E LR. More than child's play: Variable- and pattern-centered approaches for examining effects of sport participation in youth development. Dev Psychol. 2009; 45 (2): 368-382.

[8] Linver M, Roth J B-GJ. Patterns of adolescents' participation in organized activities: Are sports best when combined with other activities? Dev Psychol. 2009; 45 (2): 354-367.

[9] Hansen D, Larson R DJ. What adolescents learn in organized youth activities: a survey of self-reported developmental experiences. J Res Adolesc. 2003; 13 (1): 25-55.

[10] Consulting SC. Policy and program considerations for increasing sport participation among members of underrepresented groups in Canada: A Literature Review. 2016.

[11] UNICEF. Ethiopia's disability program key child disability facts: communication section. Addis Ababa Ethiopia; 2006.

[12] UN. Convention on the Rights of Persons with Disabilities and Optional Protocol. 2007 p. 37.

[13] Robert Blum. School Connectedness: Improving Students' Lives. 2005.

[14] Simpkins, S. D., Fredricks, J., Davis-Kean, P., \& Eccles JS. Healthy minds, healthy habits: The influence of activity involvement in middle childhood. Developmental contexts in middle childhood. Bridges to adolescence and adulthood. Ripke AH\& M, editor. New York, NY: Cambridge University Press; 2006. 